\title{
PENGARUH GAME PEMBELAJARAN TERHADAP PENINGKATAN HASIL BELAJAR PEMAHAMAN ILMU PENGETAHUAN ALAM
}

\author{
Syarif Hidayatulloh, Henry Praherdhiono, Agus Wedi \\ Teknologi Pendidkan, Universitas Negeri Malang \\ Jalan Semarang 5 Malang 65145 0341-5747001 \\ Email: syarif.hidd@gmail.com
}

\begin{tabular}{|l|}
\hline Article History \\
\hline Received:12-12-2019 \\
Accepted: 1-05-2020 \\
Published: $20-05-2020$ \\
Keywords \\
Pengaruh, Game \\
Bembelajaran, Hasil Pemahaman \\
\hline
\end{tabular}

\begin{abstract}
Abstrak
Tujuan dari penelitian ini yaitu untuk menguji adanya perbedaan hasil belajar pemahaman antara siswa yang menggunakan game pembelajaran dengan siswa yang tidak menggunakan game pembelajaran pada mata pelajaran Ilmu Pengetahuan Alam materi suhu dan perubahannya kelas VII MTs Raudlatul Ulum Karangploso. Metode penelitian yang digunakan adalah metode kuasi eksperimen Nonequivalen Control Group Design. Penelitian ini melibatkan 2 kelas yaitu kelas eksperimen dan kelas kontrol. Kelas ekperimen diberikan perlakuan menggunakan game pembelajaran, sedangkan kelas kontrol menggunakan pembelajaran ceramah. Masing-masing diberikan pretest dan posttest. Hasil pengolahan data menunjukkan perhitungan nilai rata-rata post test dari kelas eksperimen sebesar 75,35 sedangkan kelas kontrol 63,21. Kesimpulan hasil penelitian yaitu terdapat perbedaan hasil belajar pemahaman antara kelompok yang menggunakan game pembelajaran dengan kelompok yang tidak menggunakan game pembelajaran. Hasil belajar pemahaman siswa yang menggunakan game pembelajaran lebih tinggi dibandingkan dengan kelompok yang tidak menggunakan game pembelajaran.
\end{abstract}

\section{Abstract}

The purpose of this study is to examine the differences in understanding learning outcomes between students who use learning games and students who do not use learning games on Natural Sciences subjects temperature material and changes in class VII MTs Raudlatul Ulum Karangploso. The research method used is a quasi-experimental Nonequivalent Control Group Design method. This research involves 2 classes, namely the experimental class and the control class. The experimental class was treated using a learning game, while the control class used lecture learning. Each was given a pretest and posttest. The results of data processing showed that the calculation of the average post-test score of the experimental class was 75.35 while the control class was 63.21. The conclusion of the research is that there are differences in understanding learning outcomes between groups that use learning games and groups that do not use learning games. Learning outcomes for students who use learning games are higher than those who do not use learning games. 


\section{PENDAHULUAN}

Perkembangan ilmu pengetahuan dan teknologi terasa dampaknya dalam berbagai bidang kehidupan manusia, termasuk dalam dunia pendidikan (Zuhriyah,2016). Perkembangan IPTEK dalam bidang pendidikan menuntut proses pembelajaran di kelas agar lebih inovatif dan menarik dalam menyampaikan materi. Perkembangan teknologi menuntut pembelajar menjadi kreator dan fasilitator pada proses pembelajaran (Priana, 2017).

Sejalan dengan Perkembangan IPTEK, gaya belajar siswa sekarang mengalami perubahan. Siswa sekarang termasuk ke dalam generasi $\mathrm{Z}$ atau biasa disebut digital native. Menurut MCCRINDEL (generationz.com.au) mengatakakan bahwa anak generasi $\mathrm{Z}$ merupakan generasi global, sosial, visual, dan teknologi. Anak digital native memiliki beberapa perbedaan dengan generasi sebelumnya, mereka tumbuh bersama dengan teknologi digital yang sudah maju, memiliki gaya belajar yang berbeda, serta sikap baru terhadap proses pembelajaran.

Pembelajaran adalah salah satu usaha menciptakan situasi belajar sehingga pebelajar dapat meningkatkan kemampuannya (Jamaludin, 2015). Dalam kegiatan pembelajaran guru sebaiknya mampu memahami kemampuan dan kesiapan siswa dalam pelajaran yang akan disampaikan, serta mampu mengetahui kondisi siswa itu sendiri. Siswa yang memiliki kemampuan memahami pelajaran yang akan dipelajari akan menentukan keberhasilannya menguasai materi pelajaran dikelas. Pemilihan metode pembelajaran yang tepat akan dapat membuat siswa aktif dikelas. (Nanang, 2017).

Apabila guru masih menggunakan metode pembelajaran dengan cara lama atau menggunakan metode ceramah, maka hal tersebut terasa sulit. Guru harus menggunakan metode pembelajaran yang berbeda dan pendekatan yang memungkinkan peserta didik aktif serta pembelajaran menjadi lebih efektif. Suatu pembelajaran dapat efektif jika menggunakan metode pembelajaran serta media pembelajaran yang cocok dengan gaya belajar pesertanya (Pratama, 2017). Jadi dibutuhkan sebuah inovasi dalam cara mengajar seperti penggunaan media pembelajaran agar pelajaran dapat dipahami oleh siswa. Media pembelajaran adalah sebuah alat yang berfungsi untuk menyampaikan pesan, sehingga bisa membuat orang yang menerimanya terangsang pikiran serta minatnya dalam belajar (Sadiman, 2014).

Guru dalam melaksanakan pembelajaran harus kreatif dalam memilih media pembelajaran. Penggunaan media pembelajaran harus sesuai dengan pelajaran yang akan dipelajari. Penggunaan yang tepat oleh guru dapat menanamkan pemahaman konsep materi yang baik kepada siswa. Media pembelajaran juga dapat membantu guru agar tujuan pembelajaran dapat tercapai.

Observasi yang dilakukan peneliti di MTs Raudlatul Ulum Karangploso kelas VII mata pelajaran IPA, bahwa dalam proses pembelajaran dikelas guru menggunakan metode ceramah. Hal tersebut bertolak belakang dengan kurikulum yang diterapkan, yaitu Kurikulum 13. Dimana seharusnya pembelajaran berpusat kepada peserta didik bukannya berpusat kepada guru. Kurangnya penggunaan media pembelajaran di kelas mengakibatkan peserta didik kurang memahami konsep materi. Selain itu, peserta didik juga merasa bosan karena harus mendengarkan penjelasan guru selama proses belajar mengajar. Menurut (Suprijono, 2009) guru dalam melaksanakan kegiatan pembelajaran dituntut untuk kreatif menggunakan media pembelajaran.

Contoh bentuk dari media pembelajaran adalah game. Menurut Santoso (2019) Game adalah media bagi anak-anak untuk bisa mendapatkan pembelajaran yang memuat perkembangan kognitif, sosial, emosional, dan fisik. Game pembelajaran didalamnya perlu dibuat sebuah tantangan dan motivasi agar game tersebut menjadi menarik (Samsul, 2016). Game banyak sekali mengalami pengembangan dari awal ditemukan (Wifda, 2015).

Menurut Alessi \& Trollip (2001) game memiliki berbagai macam keuntungan bagi lingkungan belajar, game mampu memberikan motivasi dalam diri pada peserta didik, dalam beberapa kasus bahkan mendorong peserta didik untuk belajar, serta game membuat proses belajar menjadi lebih menyenangkan. 
Game pembelajaran adalah media pembelajaran yang menggunakan komputer dan mulai digunakan dalam proses pendidikan formal maupun non-formal. Menurut Ramadhan, dkk (2019) Game pembelajaran merupakan sebuah aplikasi permainan yang terdapat materi-materi ataupun informasi yang bersifat mendidik. Materi ataupun informasi tersebut dapat secara langsung tersurat dalam aplikasi multimedia dan dapat juga secara tersirat melalui alur cerita permainan dalam aplikasi itu sendiri. Penggunaan game dapat membuat siswa termotivasi dan membuat pembelajaran menyenangkan apabila juga mengikutsertakan siswa. Beberapa kelebihan game pembelajaran dari pada media konvensional, kelebihan dari game pembelajaran dibandingkan dengan media pembelajaran yang lain adalah penggambaran dari sebuah permasalahan yang ada (Vitianingsih, 2016). Hasil penelitian yang dilakukan oleh Malsani, didapatkan hasil bahwa ada peningkatan hasil belajar siswa yang positif dengan menggunakan game dalam kegiatan belajar mengajar.(Maslani, 2016).

Peneliti memilih mata pelajaran IPA materi suhu dan perubahannya. Banyak siswa yang beranggapan bahwa pelajaran IPA itu adalah pelajaran yang kurang menyenangkan. Peserta didik mengaku sulit memahami konsep dalam IPA, dikarenakan terkadang guru hanya menjelaskan apa yang tertulis dibuku dan tidak ada media yang menyenangkan siswa. Guru lebih banyak berperan sebagai informan dan materi-materi yang dirasa penting hanya dicatatkan di papan tulis. Akibatnya siswa yang mengikuti pelajaran akan bosan. Diperlukan sebuah media pembelajaran yang mampu menarik perhatian siswa agar aktif dikelas, contohnya adalah game pembelajaran .

Penggunaan game pembelajaran dalam proses belajar mengajar akan mempermudah siswa memahami konsep dalam mata pelajaran IPA. Karena menurut penelitian, game dapat meningkatkan logika dan pemahaman pemain terhadap mata pelajaran tersebut. Sekarang juga game banyak dimainkan oleh anak-anak usia sekolah. Dengan menerapkan game dalam proses belajar mengajar dapat meningkatkan motivasi dan minat belajar siswa.

Berdasarkan penjelasan tersebut, peneliti ingin mengadakan penelitian tentang Pengaruh Game Pembelajaran Terhadap Hasil Belajar Pemahaman IPA

\section{METODE}

Penelitian ini menggunakan metode kuasi eksperimen. Kuasi eksperimen ada dua bentuk desain yaitu : Times-Series Design dan Nonequivalen Control Group Design (Sugiyono, 2014) . Peneliti menggunakan Nonequivalen Control Group Design. Penelitian dibagi ke dalam dua kelompok yang telah ditentukan sebelumnya, yaitu kelompok eksperimen dan kelompok kontrol.

Penelitian dilakukan pada siswa kelas VII MTs Raudlatul Ulum Karangploso. Subjek yang digunakan adalah siswa kelas VII B dan VII C tahun ajaran 2019/2020 yang berjumlah 56 siswa. Kelompok eksperimen akan menerapkan pembelajaran menggunakan game pembelajaran yaitu kelas VII B. Sedangkan kelompok kontrol akan menerapkan pembelajaran sepeti biasanya yaitu dengan metode ceramah yaitu kelas VII C. Masing-masing kelas berjumlah 28 siswa.

Instrumen yang digunakan adalah sebagai berikut : 1) Rencana Pelaksanaan Pembelajaran (RPP). Dalam penelitian ini akan dibuat 2 RPP berbeda untuk 2 kelas, yaitu untuk kelas eksperimen dan kelas kontrol. 2) Game Pembelajaran. Game pembelajaran yang digunakan dalam penelitian ini adalah game yang bertipe adventure atau petualangan. Tujuan dari game adalah dengan mengumpulkan koin sebanyak-banyaknya dan juga mengumpulkan kunci. Setiap kunci berisikan materi pelajaran. Pada akhir permainan akan diketahui berapa banyak koin yang dikumpulkan. 3) Soal Tes. Untuk memenuhi tujuan dari penelitian ini, yaitu melihat ada tidaknya perbedaan tingkat pemahaman antara kelas yang menerapkan game pembelajaran dengan kelas yang tidak menerapkan media game pembelajaran, maka peneliti menggunakan objective test (tes pilihan ganda). Akan dibuat dua tes, yaitu untuk pre-test dan post-test, masing-masing soal 20 butir.

Analisis data pada penelitian terdiri dari dua tipe, yaitu uji prasyarat analisis data serta uji hipotesis dengan bantuan SPSS 20. Analisis data dilakukan terhadap hasil belajar pemahaman 
siswa. Uji prasyarat analisis data terdapat 2 tahap, yaitu uji normalitas dan uji homogenitas. Kemudian dilanjutkan dengan uji hipotesis penelitian.

\section{HASIL}

Hasil penelitian menunjukkan bahwa nilai rata-rata (mean) kelompok kontrol dan kelompok eksperimen terdapat perbedaan.

Tabel 1. Deskriptif data

\begin{tabular}{cccc}
\hline & Data & Kelompok Kontrol & Kelompok Eksperimen \\
\hline \multirow{7}{*}{ Posttest } & 28 & 28 \\
& Nilai terendah & 50 & 50 \\
& Nilai tertinggi & 75 & 85 \\
& Mean & 63,21 & 75,35 \\
& Median & 65 & 75 \\
& Standar deviasi & 6,26783 & 9,12146 \\
& Varians & 39,286 & 83,201 \\
\hline
\end{tabular}

\section{Uji Normalitas}

Uji normalitas dilakukan pada kedua kelompok eksperimen dan kontrol menggunakan uji Kolmogorof Smirnov.

Tabel 2. Uji Normalitas

One-Sample Kolmogorov-Smirnov Test

\begin{tabular}{llrrrr}
\hline & & Nilai Pre Test & Nilai Pre Test & Nilai Post Test & \multicolumn{2}{c}{ Nilai Post Test } \\
& & Kontrol & Eksperimen & Kontrol & Eksperimen \\
\hline $\mathrm{N}$ & & 28 & 28 & 28 & 28 \\
& Mean & 39,1071 & 46,0714 & 63,2143 & 75,3571 \\
Normal Parameters & & & & \\
& Std. & & & & \\
& Deviation & 8,28358 & 11,16850 & 6,26783 & 9,12146 \\
& Absolute &, 190 &, 148 &, 184 &, 207 \\
Most Extreme Differences & Positive &, 150 &, 148 &, 174 &, 158 \\
& Negative &,- 190 &,- 137 &,- 184 &,- 207 \\
Kolmogorov-Smirnov Z & & 1,006 &, 784 &, 971 & 1,096 \\
Asymp. Sig. (2-tailed) & &, 263 &, 570 &, 302 &, 181 \\
\hline
\end{tabular}

Diperoleh nilai signifikasi kelas eksperimen 0,181 dan nilai signifikansi kelas kontrol 0,302. Nilai signifikasi kelas eksperimen dan kelas kontrol lebih tinggi dari sig 0,05. Ini membuktikan bahwa data berdistribusi normal.

\section{Uji Homogenitas}

Uji homogenitas menggunakan Homogenity of Variance Test. Dengan kriteria data dikatakan homogen jika nilai sig. lebih tinggi dari 0,05 .

Tabel 3. Uji Homogenitas.

Test of Homogeneity of Variances

\begin{tabular}{|r|r|r|r|}
\multicolumn{5}{c}{ Post } \\
\hline $\begin{array}{r}\text { Levene } \\
\text { Statistic }\end{array}$ & df1 & df2 & Sig. \\
\hline, 784 & 1 & 54 &, 380 \\
\hline
\end{tabular}


Dari tabel 3 diperoleh nilai signifikansi sebesar 0,380. Nilai tersebut lebih tinggi dari 0,05 . Ini membuktikan bahwa data homogen.

\section{Uji Hipotesis}

Menggunakan Independent Sample T-test. Pengujian didasarkan pada hipotesis berikut.

$\mathrm{H}_{1}$ : (ada perbedaan hasil belajar pemahaman yang signifikan antara siswa yang belajar menggunakan game pembelajaran dengan siswa yang tidak menggunakan game pembelajaran)

Kriteria keputusan : Jika nilaiSig. (2-tailed) $<0,05$ maka $\mathrm{H}_{1}$ diterima

Tabel 4. Uji Hipotesis

Independent Samples Test

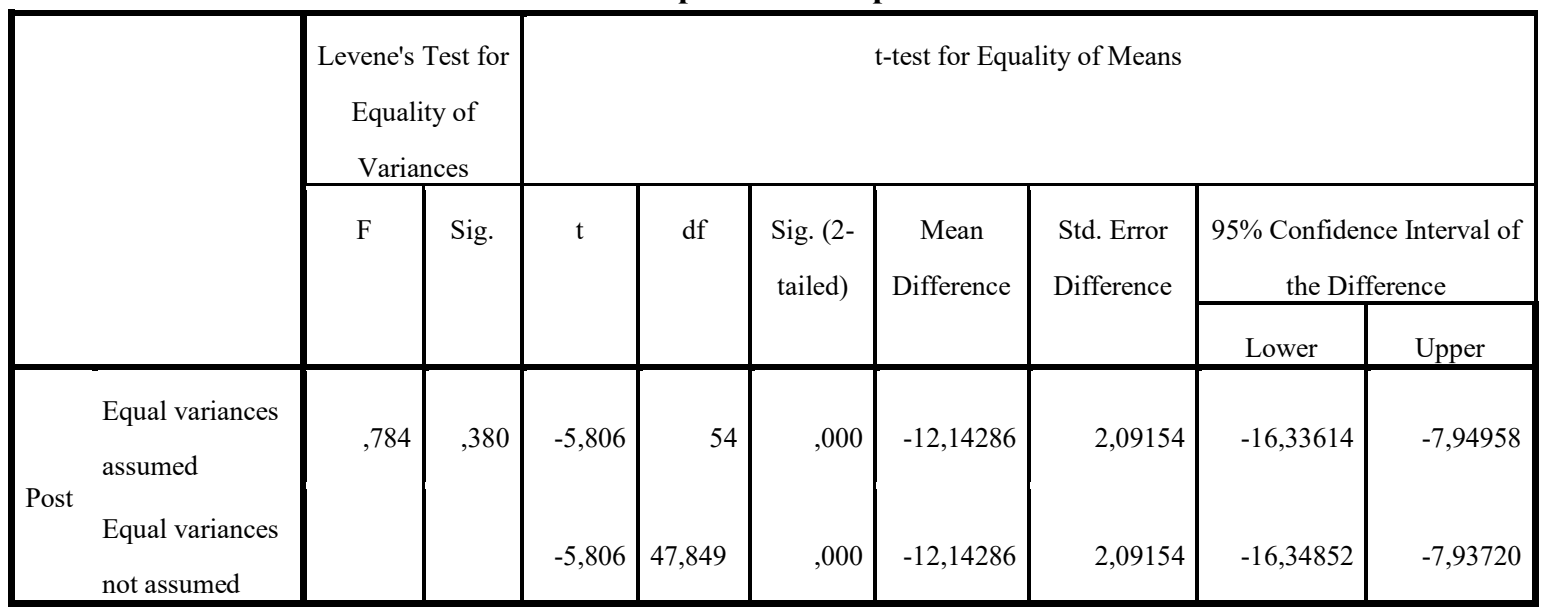

Dari tabel 4 didapatkan nilai Signifikansi (2-tailed) adalah 0,000. Nilai 0,000 lebih rendah dari 0,05 . Ada perbedaan hasil belajar pemahaman yang signifikan antara siswa yang belajar menggunakan game pembelajaran dengan siswa yang tidak menggunakan game pembelajaran.

\section{PEMBAHASAN}

Berbagai upaya dapat dilakukan untuk meningkatkan kemampuan siswa, salah satunya adalah dengan menggunakan game dalam kegiatan belajar mengajar. Penelitian yang dilakukan oleh (Lestari, Widiyatmoko, Alimah, \& Juliyani, 2015) menunjukkan bahwa penggunaan game dalam proses pembelajaran dapat meningkatkan kemampuan para siswa. Game pembelajaran dapat menarik perhatian siswa sehingga membuat siswa lebih termotivasi dalam belajar. Selain itu, siswa juga akan lebih aktif dalam mengikuti kegiatan belajar mengajar.

Game merupakan contoh bentuk dari media digital. Media digital dapat dibuat, dilihat, didistribusikan, dimodifikasi dan bisa bertahan pada perangkat elektronik digital. Teknologi digital menawarkan banyak peluang untuk membuat konten yang menarik (Tabor, 2013). Pendekatan menggunakan teknologi media digital sebagai media pembelajaran memiliki dampak yang lebih baik dan lebih efektif daripada pendekatan lain (Reeves, 1998). Menurut (Lee, 2015) dalam hal interaksi sosial dan kolaborasi, penggunaan media digital (iPad \& game) yang dilakukan di pusat pembelajaran dapat meningkatkan frekuensi interaksi antara anak-anak, baik dengan teman atau dengan guru.

Itu terjadi karena ketika mereka mendapatkan pengalaman baru (baik dalam bentuk kesulitan atau solusi), mereka cenderung berkomunikasi dengan guru dan teman mereka. (Rutten, Van Joolingen, \& Van Der Veen, 2012) juga menyatakan bahwa penggunaan media digital (simulasi komputer) dapat meningkatkan kemampuan siswa, terutama untuk bahan kerja laboratorium. Selain itu, ada perkembangan motivasi belajar pada anak-anak karena penggunaan media digital menarik dan menyenangkan (Lee, 2015). (Kocadere \& Çağlar, 2015) juga menyatakan bahwa siswa merasa lebih 
menikmati dan termotivasi dalam belajar ketika menggunakan media digital (game). Media digital juga secara efektif dapat membantu mempraktikkan beberapa teori pembelajaran penting yang dikembangkan (Pischetola \& Cattolica, 2011).

Game ini adalah konsep luas yang mengacu pada semua struktur game yang terdiri dari aturan, tujuan, dan tantangan yang dibuat untuk pengalihan atau hiburan (Cheng, Chen, Chu, \& Chen, 2015). Hingga saat ini, permainan telah berkembang secara bervariasi. Saat ini, sebagian besar orang didorong untuk menggunakan game sebagai sarana bermain dan hiburan (Felicia \& Jabbar, 2016).

Sekarang ini banyak sekali yang memainkan sebuah game sebagai hiburan. Hal ini bisa diterapkan dalam kegiatan belajar mengajar dikelas. Menurut (De Aguilera \& Mendiz, 2003) manfaat menggunakan game dalam kegiatan belajar mengajar tidak perlu diragukan. Dalam hal ini game dapat membangkitkan motivasi, melatih keterampilan, juga mampu meningkatkan persepsi dan stimulasi serta mampu mengembangkan kemampuan pengguna dalam menyelesaikan masalah. Selain itu, game juga dapat mengembangkan penilaian kemampuan suatu strategi, mengatur media dan alat untuk mendapatkan jawaban / solusi cerdas. (Dondlinger \& Dondlinger, 2007) juga menyatakan bahwa game dapat memiliki efek positif pada proses pembelajaran, meskipun ada konsensus luas bahwa permainan hanya memotivasi pengguna untuk menguasai keterampilan permainan mereka.

Genre dari game ini adalah game petualangan. Game ini mampu memberikan motivasi bagi siswa untuk belajar. Penggunaan latar belakang permainan menggunakan kondisi dunia nyata juga dapat berdampak pada peningkatan motivasi bagi pemain (Kahn., 2015). Game ini terdiri dari beberapa level. Setiap level memiliki tingkat kesulitannya sendiri. Kesulitan pada masing-masing level ini dapat memicu siswa untuk menyelesaikan tantangan. (Giammarco, Schneider, Carswell, \& Knipe, 2015) menyatakan bahwa para pemain game pada dasarnya memiliki semangat dan hasrat untuk menyelesaikan setiap level permainan dan maju ke level berikutnya.

Usia siswa saat memasuki tingkat SMP di Indonesia berkisar antara usia 12-14 tahun. (Eccles, 1999) menyatakan bahwa pada anak usia 6-14 tahun (remaja menengah dan awal) adalah masa perkembangan bagi anak-anak untuk membangun identitas mereka. Pada saat ini, anak-anak bersiap untuk bergerak menuju orang dewasa dengan menjadi kompeten, mandiri dan berusaha untuk terlibat dengan dunia di luar keluarga mereka. Perubahan juga terjadi pada sisi biologis dan kognitif anak-anak. Metode pembelajaran yang tepat akan sangat membantu proses belajar anak. (Rohwati, 2012) menyatakan dalam sebuah penelitian yang dilakukan di SMP Negeri 1 Wonosobo yang menggunakan Game Edukasi terbukti meningkatkan hasil belajar dan aktivitas siswa.

Penelitian ini menunjukkan efektifnya penggunaan game pembelajaran dikelas. Game ini bergenre petualangan, dimana siswa harus mengumpulkan koin dan kunci sebanyak-banyaknya. Setiap kunci berisi materi yang dipelajari saat itu. Materi yang digunakan dalam game adalah materi suhu dan perubahannya.

Hasil penelitian menggambarkan adanya perbedaan hasil belajar pemahaman siswa yang menerapkan game pembelajaran dengan yang tidak menerapkan game pembelajaran pada siswa Kelas VII MTs Raudlatul Ulum Karangploso. Pengumpulan data dilakukan dengan membagi kelas 2 kelompok yaitu kelas kontrol dan kelas eksperimen. Kedua kelas tersebut diberikan posttest. Kelas eksperimen menggunakan game pembelajaran sedangkan kelas kontrol menggunakan metode ceramah.

Pada kolom equal variances assumed yang menunjukan nilai t hit $-5,806$ pada df 54 dengan signifikansi 0,000 , karena nilai t hitung yang diperoleh berdistribusi negatif maka kriteria $\mathrm{H}_{1}$ diterima adalah $\mathrm{t}$ hit $<\mathrm{t} \operatorname{tab}(-5,806<2,00488)$ dan nilai signifikasi $<0,05$. Hal itu berarti $\mathrm{H}_{1}$ diterima yang berarti ada perbedaan hasil belajar pemahaman yang signifikan antara siswa yang menerapkan game pembelajaran dibandingkan siswa yang tidak menerapkan game pembelajaran. 
Keadaan tersebut menunjukkan bahwa hasil belajar pemahaman kelas eksperimen melebihi nilai dari kelas kontrol. Perbedaan tersebut diakibatkan pengaruh penggunaan game pembelajaran dalam proses pembelajaran yang diberikan kepada kelas eksperimen, sehingga peserta didik tersebut memiliki nilai hasil belajar pemahaman lebih baik setelah menggunakan game pembelajaran dibandingkan kelas kontrol.

Dari hasil analisis, bahwa pembelajaran menggunakan game pembelajaran menunjukkan hasil belajar pemahaman kelas eksperimen melebihi hasil belajar kelas kontrol. Sehingga ada pengaruh game pembelajaran terhadap hasil belajar pemahaman siswa pada mata pelajaran IPA materi suhu dan perubahannya kelas VII di MTs Raudlatul Ulum Karangploso. Dapat dsimpulkan bahwa ada pengaruh yang signifikan pada hasil belajar pemahaman siswa dengan digunakannya game pembelajaran. Game pembelajaran bisa memberikan dampak yang positif bagi siswa. Selain itu, juga meningkatkan keaktifan siswa dikelas dan meningkatkan konsentrasi dalam belajar. Sesuai dengan penelitian yang dilakukan Maslani, berjudul "Meningkatkan Hasil Belajar Dan Keaktifan Siswa melalui Permainan (Game) Ranking I pada Materi Norma Dalam Kehidupan Bersama Di Kelas VII A SMPN 4 Pelaihari” menunjukkan bahwa terdapat peningkatan hasil belajar siswa.

\section{SIMPULAN}

Berdasarkan hasil penelitian dapat disimpulkan bahwa terdapat perbedaan hasil belajar pemahaman antara kelompok yang menerapkan game pembelajaran dengan kelompok yang tidak menerapkan game pembelajaran. Dimana hasil belajar pemahaman siswa yang menerapkan game pembelajaran lebih tinggi dibandingkan dengan kelompok yang tidak menerapkan game pembelajaran. Selain itu, game pembelajaran dapat meningkatkan keaktifan, minat dan motivasi siswa dalam mengikuti kegiatan pembelajaran.

\section{DAFTAR RUJUKAN}

Alessi, Stephen M., \& Trollip, Stanley R. (2001). Multimedia for Learning Methods and Development. 3rd. ed. Massachusetts : Allyn \& Bacon A Pearson Education Company.

Cheng, M. T., Chen, J. H., Chu, S. J., \& Chen, S. Y. (2015). The use of serious games in science education: a review of selected empirical research from 2002 to 2013. Journal of computers in education, 2(3), 353-375.

De Aguilera, M., \& Mendiz, A. (2003). Video games and education: (Education in the Face of a "Parallel School"). Computers in Entertainment (CIE), 1(1), 1-10.

Dondlinger, M. J. (2007). Educational video game design: A review of the literature. Journal of applied educational technology, 4(1), 21-31.

Eccles, J. S. (1999). The development of children ages 6 to 14. The future of children, 30-44.

Giammarco, E. A., Schneider, T. J., Carswell, J. J., \& Knipe, W. S. (2015). Video game preferences and their relation to career interests. Personality and Individual Differences, 73, 98-104.

Jabbar, A. I. A., \& Felicia, P. (2016). Towards a conceptual framework of GBL design for engagement and learning of curriculum-based content. International Journal of Game-Based Learning (IJGBL), 6(4), 87-108.

Jamaludin. (2015). Pembelajaran Perpsektif Islam. Bandung: PT Remaja Rosdakarya Ofset.

Kahn, A. S., Shen, C., Lu, L., Ratan, R. A., Coary, S., Hou, J., ... \& Williams, D. (2015). The Trojan Player Typology: A cross-genre, cross-cultural, behaviorally validated scale of video game play motivations. Computers in Human Behavior, 49, 354-361.

Kocadere, S. A., \& Çağlar, Ş. (2015). The design and implementation of a gamified assessment. Journal of eLearning and Knowledge Society, 11(3).

Lee, L. (2015). Digital media and young children's learning: A case study of using iPads in American preschools. International Journal of Information and Education Technology, 5(12), 947.

Lestari, A., Widiyatmoko, A., Alimah, S., \& Juliyani, I. (2015). Sounds Learning Using Teams Games Tournament With Flash Card As Media At The 13Th Junior High School Of Magelang. Jurnal Pendidikan IPA Indonesia, 4(2). 
Maslani. (2017). Meningkatkan Hasil Belajar Dan Keaktifan Siswamelalui Permainan (Game) Ranking Ipada Materi Norma Dalam Kehidupan Bersama Di Kelas VII A SMPN 4 Pelaihari. Jurnal Pendidikan Kewarganegaraan Vol. 6, No. 2.

Nanang. (2017). Pengaruh Pembelajaran Tutorial Berbasis Multimedia Interaktif Terhadap Peningkatan Motivasi Dan Hasil Belajar Siswa Pada Pokok Bahasan Statistika. Jurnal Teknologi Pendidikan Dan Pembelajaran, 190-191.

Pischetola, M. (2011). Digital media and learning evolution: A research on sustainable local empowerment. Global media journal, 10(18).

Priana, R. Y. (2017). Pemanfaatan Vlog Sebagai Media Pembelajaran. Prosiding Seminar Nasional Pendidikan, $1-2$.

Rahman, R. A., \& Tresnawati, D. (2016). Pengembangan Game Edukasi Pengenalan Nama Hewan Dan Habitatnya Dalam 3 Bahasa Sebagai Media Pembelajaran Berbasis Multimedia. Jurnal Algoritma, 13(1), 184-190.

Ramadhan, H. F., Sitorus, S. H., \& Rahmayuda, S. (2019). Game Edukasi Pengenalan Budaya Dan Wisata Kalimantan Barat Menggunakan Metode Finite State Machine Berbasis Android. Jurnal Komputer dan Aplikasi. 07(1), 108-119

Reeves, T. C. (1998). The impact of media and technology in schools. Journal of The Journal of Art and Design Education, 2, 58-63.

Rohwati, M. (2012). Penggunaan education game untuk meningkatkan hasil belajar IPA biologi konsep klasifikasi makhluk hidup. Jurnal Pendidikan IPA Indonesia, 1(1).

Rutten, N., Van Joolingen, W. R., \& Van Der Veen, J. T. (2012). The learning effects of computer simulations in science education. Computers \& Education, 58(1), 136-153.

Sadiman, Arief S., Rahardjo, R., Haryono, A., \& Harjito. (2014). Media Pendidikan (Pengertian, Pengembangan dan Pemanfaatan). Jakarta: Rajawali Pers

Samsul, A. H. (2016). Game Edukasi Cepat Tepat Dengan Metode Finite State Machine (Fsm) Pada Smartphone. Malang: Universitas Islam Negeri Maulana Malik Ibrahim.

Santoso, M. (2019). Rancang Bangun Game Edukatif Duta Indonesia (Dadu Dan Peta) Indonesia. Konstruktivisme : Jurnal Pendidikan Dan Pembelajaran, 11(1), 20-31.

Sugiyono. (2014) Metode Penelitian Kuantitatif Kualitatif dan R\&D. Bandung : Alfabeta

Suprijono, A. (2009). Cooperative Learning: Teori dan Aplikasi PAIKEM. Yogyakarta: Pustaka Pelajar.

Tabor, S. W., \& Minch, R. P. (2013). Student Adoption \& Development of Digital Learning Media: Action Research and Recommended Practices. Journal of Information Technology Education, 12.

Vitianingsih, A. V. (2016). Game Edukasi Sebagai Media Pembelajaran Pendidikan Anak Usia Dini. Jurnal INFORM Vol. 1, No. 1, ISSN: 2502-3470

Wifda, A. R. (2015). Pengembangan Game Edukasi Lingkungan Berbasis Android. Yogyakarta: Univesitas Negeri Yogyakarta.

Zuhriyah, S. (2016). Pemanfaatan Media Dalam Peningkatan Kualitas Pembelajaran. Prosiding Temu Ilmiah Nasional Guru, 522. 